\title{
ILLUSIONS OF A SPONTANEOUS ORDER: “NORMS" IN CONTRACTUAL RELATIONSHIPS
}

\section{DAVID Charny†}

\section{INTRODUCTION}

Nonlegal enforcement systems come in many varieties. The ordinary rules of everyday conduct are enforced by the gossip of neighbors and scolding of friends; while, at the other extreme of complexity, investors may comply with intricate financial arrangements mainly to preserve their market reputation, rather than from fear of lawsuit. The need for further typology is evident.

The Japanese products liability system and the transactional rules of the American grain industry-carefully described in the articles before us ${ }^{1}$-represent two variants of a particular type of nonlegal governance regime-a type in which the parties devise a fairly comprehensive system that includes written rules of conduct, sanctions, and procedures for enforcement. These systems are established in a two-step process: first, norms evolve as a result of transactors' dealings (as in the grain industry) or industry consensus (standards identifying "design defects"); second, the centralized agency selects among, codifies, and enforces these norms. The substantive rules of conduct applicable to transactions are formulated in part by courts and legislators, in part by nonlegal decisionmakers-trade organizations, independent standard setters, arbitrators. Correlatively, the sanctions imposed for violation of the rules are at first cut "nonlegal"-expulsion from the trade association or revocation of the license to use a trade emblem. In the background, courts stand ready to enforce the damages stipulated by lawexpectation damages for breach of contract and full compensation for injuries suffered in tort.

In these settings, then, the nonlegal systems both displace in part, yet rest upon, the extant legal regime. The systems represent attempts to modify the background law-the products liability regime as applied to consumer products and Article 2 of the Uniform Commercial Code (UCC) for sales of grain. At the same

† Professor of Law, Harvard Law School; Olin Fellow, Columbia Law School.

I See Lisa Bernstein, Merchant Law in a Merchant Court: Rethinking the Code's Search for Immanent Business Norms, 144 U. PA. L. REV. 1765 (1996); J. Mark Ramseyer, Products Liability Through Private Ordering: Notes on a Japanese Experiment, 144 U. PA. L. REV. 1823 (1996). 
time, the systems establish contracts that, although containing terms that may differ from background law, would be enforceable as contracts. Presumably, if the Japanese council as insurer refused to honor the insurance contract, the consumer could go to court to obtain compensation promised under the contract. The grain traders can also go to court, although the court sometimes would be bound by the contracts' arbitration provisions. And of course the myriad background rules of tort, property, and contract structure the markets within which these particular transactions occur.

Accepting the evidence provided by Bernstein and Ramseyer as to the operation of these hybrid systems, this Comment addresses some of the questions this evidence raises for our understanding of the role of norms in their relation to legal governance. What do we need to know about norms? What can we learn from the examples here? In particular, I shall comment in Parts I and II.A on the broad claim that nonlegal norms can supplant or importantly supplement "public" regulation; in Part II.B on the claims that emergent nonlegal norms are "efficient;" and in Part II.C on the claim that the legal system generally should not provide legal sanctions for violations of norms in commercial transactions.

\section{Methodological Questions: What Is at STAKe?}

The roots of the modern conception of norms in law and in economics are Hayekian. Of course, modern social theory broadly understood had been obsessed with the debate between those who saw the just social order as necessarily "constructed" centrally and by rational principles, and those who see it as proliferating benignly by spontaneous generation from the decentralized, only locally coordinated decisions of the members of society. Curiously, however, this debate had until recently been of only marginal importance in economics, and correlatively in the hybrid subdiscipline of law and economics.

In economics, the question of spontaneous generation had been a central theme of Hayek, Schumpeter, and other, lesser members of the "Austrian school." But Hayek's contribution had always

2 Important articulations of Hayek's distinction between constructed legal rules and evolved social norms are found in 1 F.A. HAYEK, LAW, LEGISLATION AND LIBERTY: RULES AND ORDER 8-34 (1973) (explaining the conflicting views that human institutions are the products of deliberate design or the results of social evolution), and F.A. HAYEK, Studies IN PHILOSOPHY, Polmics AND Economics 96-105 (1967) (discussing the role of unintended consequences of human action in social theory). 
been treated as marginal by the mainstream Anglo-American economic tradition, which culminated in the great general equilibrium theorems of the 1950s. The mathematical formalization of general equilibrium theory depended upon methods and assumptions very different from Hayek's. In particular, a central problem with integrating Hayek's insights lay in his conception of imperfect information. Hayek's conception was epistemologically far more radical than the conceptions of imperfect information built into modern principal-agent models. In Hayek's conception, the problem was not that a central planner (or indeed, many other market participants) could not predict social actors' preferences, but rather that it was not meaningful in principle to speak of these preferences until the choices had actually been made-something that could only be done by the participants themselves, not by some central planner acting on their behalf. In contrast, students of the law and economics of market relationships-particularly, those in fields that most directly address the law that bears on market transactions, like tort, contract, and regulated industries-inherited the neoclassical approach, which works from particularized informational deficiencies (or "transaction costs").

Consequently, contemporary legal and economic analysis arrives at Hayekian principles obliquely-through a multivalent conception of "norms" - while avoiding the persistently unfashionable Hayekian epistemology. In retrospect, the impetus for the move, first among economists and then among law and economics scholars, is apparent. For economists, norms first entered the picture to explain conduct of macroeconomic importance that seemed inconsistent with simple-minded utility maximization, such as the stability of work effort and wages despite aggregate economic fluctuations. ${ }^{3}$ As such apparently "irrational" conduct is pervasive in the phenomena that law addresses, the transfer of economics to law demanded a correspondingly greater emphasis on a source of conduct outside of a mere rational calculation about compliance

Useful interpretations of Hayek's thought and its importance are found in JOHN GRAY, HAYEK ON LIBERTY (2d ed. 1986), and ROLAND KLEY, HAYEK'S SOCIAL AND POLITICAL THOUGHT (1994). For related commentary in this symposium, see Robert D. Cooter, Decentralized Law for a Complex Economy: The Structural Approach to Adjudicating the New Law Merchant, 144 U. PA. L. REV. 1643 (1996) (commenting on "legal centrism").

${ }^{3}$ The leading work was George A. Akerlof, Labor Contracts As Partial Gift Exchange, 97 Q.J. ECON. 543, 544 (1982) (describing employment arrangements as "giftexchanges" based on norms of behavior). 
with extant legal sanctions, which as a practical matter are often minimal even for seriously harmful conduct. In short, one needed to preserve the "rational actor" paradigm in the face of all sorts of conduct that did not seem particularly rational. ${ }^{4}$ Explaining that individuals were responding to the pressures of the nonlegal sanctions that attached to violations of nonlegal specified norms provides a prolific means for doing so: particularly because one can, in principle, posit a "sanction," such as shame before others or a guilty conscience, that has whatever force is required to explain the conduct at issue.

But the rhetoric of "norms" has served a second-dare one say more overtly political?-function. Again, the connection is tight with the move towards "imperfect information" economics, or more generally with an economics that moves from a richer description of human agency than the standard perfectly informed utilitymaximizer. The difficulty arises with the political consequences of the new economics-consequences that will lead us (at the end of this Comment) to see the wisdom of the Hayekian approach to the economistic vindication of conservative principles. It should be remembered that even the most radically collectivized of economic systems could be built on strictly neoclassical economic principles. For every market, it came to seem, there was a market failure; and for every market failure, a prescription for legal regulation or public provision. The move to collectivism seemed to proceed even more readily as individual agents were more cogently characterized as ignorant and irrational: for then it was harder to explain the advantages of decentralized as against centralized decisionmaking. Indeed, advantages of centralized information gathering and deliberation might improve the rationality of collective over individualized decisionmaking.

"Norms" help to assure the conservative or anti-collectivist that the limited laissez-faire approach of an austere common law regime can achieve the proverbial best of both worlds. A nonlegal norm system can aggregate the insights of a large number of individual actors through mechanisms for the "evolution" of norms through

${ }^{4}$ More recently, irrational conduct has been detected even, for example, in what were supposedly the most rational of markets, such as those dealing in securities. See, e.g., Thomas Russell \& Richard H. Thaler, The Relevance of Quasi Rationality in Competitive Markets, in RICHARD H. THALER, QUASI RATIONAL ECONOMICs 239, 239-57 (1991) (describing the implications of rational and less-than-fully rational agents interacting in competitive markets). 
some principle of rational selection. ${ }^{5}$ Although decentralized, a nonlegal norm system might produce conduct that reflected the comparatively greater degree of enlightenment of the normgenerating procedures. In turn, as we just saw, the availability of a system of nonlegal sanctions for violation of the rules of conduct specified by the norm system would explain in terms of "rationality" why individuals often acted in ways that seemingly departed from rational self-interest.

Thus, the research program must specify the mechanisms by which norms-particularly "efficient" norms-are formulated and the procedures and sanctions by which norms are enforced.

\section{ANALYSIS OF NORMS: EVIDENCE FROM TRANSACTIONAL SYSTEMS}

\section{A. Where Do Norms Come From?}

An efficiency claim for norms should depend on some account of how the procedures that generate norms are likely to generate efficient norms. A problem with the literature to date has been the sheer diversity of types of nonlegal normative systems. Indeed, one might question whether it is useful to use the same term ("norms") for comprehensive and relatively complex regimes as for more informal and diffuse sanctioning systems. With the systems that Bernstein and Ramseyer describe, we are quite far from the bucolic expanses of Shasta County or the watery wastes of the Great Banks, whose regimes are most remarkably characterized by the sporadic nature of the parties' interactions and the absence of a centralized agency for formulating or enforcing rules. For the transactions here, in contrast, we have such a "state-like" agency-indeed, in the Japanese consumer liability case, an agency created by the state-that regulates a dense network of sophisticated transactions.

A key feature for distinguishing among nonlegal sanctioning systems is the type of conflict of interest among participants in the systems. We should distinguish transactional systems-consumer products in Japan, grain and feed in the United States-from two other types: what I would call common-pool and external-harms systems. In transactional systems, conflicts of interest arise because

${ }^{5}$ See, e.g., Robert C. Clark, Contracts, Elites, and Traditions in the Making of Corporate Law, 89 COLUM. L. REV. 1703, 1712-18 (1989) (describing three sources of norms and the dominance of the contractual model in the creation of norms). 
of the disputes among the parties about an exchange of goods or services. In common-pool systems, the parties face conflicts of interest even in the absence of transactions among themselves because all draw on a common pool that will be too quickly exhausted unless the participants' conduct is regulated. ${ }^{6}$ In external-harms systems, in contrast, the parties neither routinely deal with one another nor routinely engage in conduct that requires regulation because of its impact on other participants; but they are in a relationship-such as the fabled railroad and farmer ${ }^{7}$-in which they may occasionally do harm to each other.

Both the common-pool and external-harms systems involve production of public goods by regulating participants' conduct. Note, however, the difference between the harms that each participant does to the other in these two systems. In the commonpool system, no single act of a party does substantial harm to another; rather, it is the accumulation of the conduct of all parties over time that must be regulated. In the external-harms system, single acts cause substantial, identifiable harm to other participants-as when the railroad spark ignites a field of crops.

These structural differences are important to the relative effectiveness of the norm systems. The transactional setting should be a particularly favorable environment for the development of effective norm systems. Repeated transactions provide ready opportunities for discipline of norm violators: the trading partner may break off the transaction, and potential traders may refuse to deal with the evildoer. Further, harms done in the course of transaction are easily detected. Finally, the common features of transactions will generate common regulatory interests among participants. These features will be lacking in the classic common-pool and external-harms cases, unless the participants in the latter systems also happen to develop a thick network of trading relationships. ${ }^{8}$

When one comes to formalization and centralization of norm development and enforcement-the National Grain and Feed

${ }^{6}$ The soon-to-be-classic discussion is ELINOR OSTROM, GOVERNING THE COMMONS: THE EVOLUTION OF INSTITUTIONS FOR COLIECTIVE ACTION (1990).

${ }^{7}$ For an insightful analysis of this fable, see Eric A. Posner, Law, Economics, and Inefficient Norms, 144 U. PA. L. REV. 1697 (1996).

${ }^{B}$ For example, Ellickson emphasizes that he expects that efficient norms are most likely to evolve among members of a "close-knit community." See ROBERT C. Ellickson, ORder WITHOUT LAW: HOW NeIGHBors SETTLE DisPUTES 184-206 (1991). In a sense, the ties among members of this community replace the disciplines that would naturally arise in a network of trading relationships. 
Association (the "NGFA"), the Japanese Product Safety Council-a different picture emerges. Formalization and centralization are public goods that no individual transactor has adequate incentives to develop if she adverts solely to her transactional interests. In this sense, these goods are on par with the regulatory fruits of the common-pool and external-harms systems; and one's ready faith in the transactional systems' spontaneous emergence from private marketplace activity therefore breaks down. Formalization and centralization will emerge only after public action-the initiative of the state agency-or after a form of organizational entrepreneurship that is political in motivation-motivated, for example, by a vision of social order whose realization the individual takes as a good even beyond its direct material benefit to him. ${ }^{9}$ Thus, the NGFA and like agricultural organizations emerged from the agrarian populist movements of the nineteenth century. ${ }^{10}$

The political impulse towards organization is crucial because merely decentralized, spontaneously generated norms are unlikely to be of use in complex, geographically dispersed, mass markets. The evidence for this is clear in the cases before us. The NGFA formalized norms in order to achieve uniformity in the national market, so that geographically dispersed traders could rely on dealing with each other under a common set of standards. Similarly, the key feature of the Japanese products systems are the simple insignias (" $S$ " and " $S G$ ") available at first to all domestic products, and now to imported goods as well. Enforcement of the norms is also now accomplished through unified procedural systems established by these centralized agencies. Evidently, mere decentral-

${ }^{9}$ The good may derive either from a sense of altruism, from a pleasure in accomplishment or imposition on others, or from a sheer enjoyment in the process of political organization itself. See generally HANNAH ARENDT, ON REVOLUTION (1963) (providing a classic discussion of conceptions of political action as an inherent good).

${ }^{10}$ In more traditional societies, centralizing and formalizing tendencies may arise from common religious or ethnic affiliations as well. Examples in the literature include groups as diverse as the ethnic Chinese in South Asia, orthodox Jewish diamond traders, monastic producers of Bordeaux wine, and Maghrebi merchants. See, e.g., Lisa Bernstein, Opting Out of the Legal System: Extralegal Contractual Relations in the Diamond Industry, 21 J. LEGAL STUD. 115 (1992) (describing the relations of traders in the New York diamond industry in resolving disputes); Janet T. Landa, $A$ Theory of the Ethnically Homogeneous Middleman Group: An Institutional Alternative to Contract Law, 10 J. LEGAL STUD. 349 (1981) (describing the function and structure of Chinese middleman groups and how these groups reduced transaction costs and facilitated exchanges in the absence of contract laws). 
ized generation and enforcement of norms is too fragmented and haphazard to achieve effectiveness across large markets.

\section{B. Are Norms Efficient?}

In the absence of a reliable metric for determining the substantive efficiency of particular norms, it seems crucial to be able to point to features in the process of norm generation and enforcement that at least suggest that the resulting norms would be efficient. In the cases before us, however, the efficiency of norm formulation is puzzling. The formulators here are not the innocently decentralized village gossips described in many parables about norms; they are sophisticated political organizations apparently dominated by cohesive groups whose members share a common interest. In terms of "public choice" theory, then, we have an almost formulaic situation for generating inefficient norms-norms that favor the members of the concentrated interest groups, at the expense of more diffuse members. An account of these organizations as efficient, then, must prescind from standard public choice theory's disdain of political activity as mere predatory rent-seeking. What is it about this "norm" setting, then, that might provide assurance that an efficiency theorem for norms might go through?

The Japanese consumer products system provides a relatively simple case for analysis. Note that producers voluntarily opt in to the system. Presumably, they do so when the SG label will help them sell products to consumers, increasing sales enough to justify whatever costs of compliance are incurred in qualifying for the label. ${ }^{11}$ If consumers are well informed about what the SG label means, then, clearly the labelling system induces an optimal level of safety in consumer products.

Unfortunately, then, key aspects of the system remain shrouded in the inscrutability with which the Orient remains vulgarly associated, despite the best efforts of researchers like Ramseyer to explain its puzzling features. In the case at hand, for example, neither Japanese consumers nor we know much about the substance of the liability standard or the procedures for assessing claims. The safety "norms" were formulated by an expert tribunal and adopted unilaterally, and there is no evidence that the consumers had any knowledge of them. One must wonder, given this dearth of

\footnotetext{
${ }^{11}$ More technically, when the benefits to the consumer of the regime outweigh the costs to the manufacturers of subjecting themselves to it.
} 
information, whether consumers themselves are in a position to make intelligent decisions about the value of the warranty protections offered. ${ }^{12}$

Further, one can hypothesize that in some circumstances manufacturers clearly gain from this norm-generating and -enforcing system, even if it does not offer protections that consumers rationally can value. Of course, it may be that consumers are simply fooled into attaching value to these protections-like our own "Good Housekeeping" seal of approval. ${ }^{13}$ Or the industry may see the system as a promising way of avoiding other litigation. Here the analogy to workers' compensation is suggestive. On standard public choice theory, the most plausible explanation for widespread adoption of workers' compensation would be the power of concentrated interest groups-here, the large industrial manufacturers-to reduce their liability for industrial accidents by substituting cheap, low-recovery liability systems for the procedurally costly and potentially high-recovery tort system. ${ }^{14}$

The grain and feed industry provides a harder case both for explaining why the norms might be efficient and for assessing whether they are or not. One problem is that-unlike the Japanese product liability case-the grain and feed industry provides no competitive choice between transactors who subject themselves to the rules and those who do not. Unlike the Japanese consumer, the buyer or seller of grain cannot choose to transact either with a partner who is subject to the norms or with one who may depart

12 Of course, consumers have a number of informal methods for getting information, such as word-of-mouth anecdotes gleaned from friends. If the accident rate is as low as postulated by Ramseyer in his hypothetical case, however, it seems unlikely that most consumers have even this sort of indirect contact with the system; surely, it would be unlikely that a potential consumer would know anyone who had actually had experience, either favorable or unfavorable, with the claims system.

${ }^{13}$ Is it rational to put much stock in a system about which one has almost no information? Faced with the well-accepted body of evidence on the irrationality of decisionmaking in the most ordinary contexts, see, e.g., RICHARD NISBETT \& LEE ROSS, HUMAN INFERENCE: STRATEGIES AND SHORTCOMINGS OF SOCIAL JUDGMENT 273-96 (1980), and the contestability of conceptions of rationality themselves, see, e.g., ALLAN

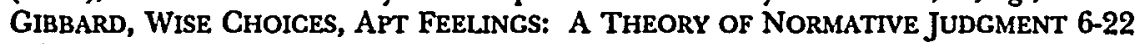
(1990), it seems ill-advised to proceed to draw social conclusions by assuming that apparently ill-informed consumers are rational in the economic sense of maximizing expected utility.

"In particular, this fits with the growing popularity among manufacturers of "industrial compensation systems" as the courts eroded the common law defenses provided by the fellow-servant rule, contributory negligence, and assumption of risk. The historical background is described by Richard A. Epstein, The Historical Origins and Economics of Workers' Compensation Law, 16 GA. L. REv. 775 (1982). 
from them with impunity. Thus, the competitive pressures toward efficient choice of norms-that transactors faced with alternative menus of rules will choose the most desirable ones-are simply absent.

A second complicating feature for analysis lies in the process by which norms are chosen for institutional enforcement. While we do not know how the Product Safety Commission goes about defining "defect," we have some sense-thanks to Bernstein's pioneering work-about how the NGFA determines its norms. Apparently, norms emerge in two stages. First, norms in a sense emerge "spontaneously" as a result of the conduct of dispersed transactors. Second, the NGFA selects some of these norms for codification and/ or arbitral enforcement. An efficiency claim requires that one assess the process at each stage. First, in the evolution of norms, selection of norms must be efficient: for example, norms must be selected by the standard mechanism of individuals choosing to transact with partners who follow the desired norms. Second, in selection of norms for enforcement, the organization must be free of rent-seeking and reasonably well informed by some deliberative process.

Nonetheless, in the face of these complexities, one can construct an argument in theory that the industry has an incentive to adopt the optimal set of norms. Two types of arguments-corresponding to two slightly different sets of "stylized facts"-are available here. ${ }^{15}$ First, the familiar argument about the efficient production choices of monopolists may extend to this case. Recall that the monopolist exploits his monopoly power by raising prices, not by adopting onerous (that is, inefficient) contract terms. To the extent that a group of traders are intelligently exerting monopoly power vis-à-vis outsiders-at either stage of the process of norm formulation-one would expect like behavior: the group would raise prices, not impose onerous trading terms. This requires, however, that insiders be in a position to discriminate in price between other insiders and outsiders; it is not clear how this form of cartelization would be sustained in a many-participant market for relatively homogeneous commodities like grain.

Second, it may be that there are simply no outsiders to be potential victims of monopolistic practices: all traders are members

15 The analysis here is a subset of the broader problem of the efficiency of group norms vis-à-vis outsiders; my analysis applies to cases of transactional norms. For remarks about the problem in other settings, see Posner, supra note 7, at 1708-09. 
of the rule-setting groups. In terms of efficient norms, there are then two subcases to consider. In one case, the traders are alternately buyers, sellers, middlemen, and so forth: that is, they engage indiscriminately in the various transactional roles and thus have no special interest peculiar to their trading status. This sharing of roles accomplishes stochastically a type of Rawlsian "veil of ignorance": not knowing which role will predominate in future transactions, the transactors will abstract from the partial (distributive or rent-seeking) interests that various subgroups of buyers, sellers, and so forth might have; instead, they will simply favor the rule that minimizes costs over all groups.

In the other subcase, traders break down into subgroups-there are distinct groups of traders who are predominantly buyers, sellers, or middlemen-but mechanisms come into play to thwart rentseeking. For spontaneous emergence of norms, perhaps the dispersal of numerous transactors prevents coordination to impose inefficient norms; for institutional selection, the NGFA's apparatus may be designed sagaciously to prevent predominance by any particular subgroup that seeks to promote its private interests.

In the grain and feed case, traders apparently have heterogeneous interests. Although they assume multiple roles (buyers and sellers), we do not know whether one role would tend to predominate for each trader, thereby defining his interests in terms of that role. Presumably, some traders clearly see themselves as primarily buyers or sellers-farmers who raise grain are sellers, end-users of grain are buyers. Further, we face a clear demarcation between "large" and "small" traders: the large traders are defined as those whose transactions are sufficiently numerous to support a bureaucratic hierarchy of managers who presumably supply informationprocessing, organizational, and legal expertise to those below. All of this describes a group sufficiently heterogeneous to make one skeptical that any of the simple mechanisms for generating efficient norms are operating. Bernstein identifies this set of questionsparticularly, the distinct interests and influences of large and small traders-as important questions for future research, and I agree. Suffice it for now to conclude that, in this carefully described milieu for norm generation, the efficiency hypothesis requires substantial further research before it can enjoy even tentative assent.

As one turns norm formulation to norm enforcement, the attempt to assess efficiency reaches equally puzzling results. Presumably, the informal arbitration procedures are cheaper, on a case-by-case basis, than would be a corresponding full judicial trial 
of the same issues. It may be that these informal tribunals are "expert" and therefore more accurate, although, curiously, both Bernstein and Ramseyer ask us to take these assertions on faith. ${ }^{16}$ It may simply reflect lawyers' own cult of expertise that they are so ready to assume that other specialists, such as lay commercial arbitrators or standard setting agencies, are equally expert-despite a growing body of literature that raises deep questions about such claims of expertise. ${ }^{17}$ One would like to know about what the "specialists" actually "know," and also about protections against the bias that is familiar in other arbitral settings, such as those involving employment and securities claims.

Even stipulating that these informal hearings are cheaper and somewhat more accurate than trials, there remains a question whether these adjudicatory systems taken as a whole are cheaper for the participants than recourse to judicial proceedings. It may be, for example, that the availability of cheaper and simpler proceedings encourages parties to "litigate" many cases that they could readily settle among themselves, if the only alternative were the more expensive judicial suit. "Repeat transactors" may prefer arbitration simply because they believe that they enjoy an advantage over one-shot transactors in dealing with the arbitral establishment; repeat transactors can generally impose such an advantageous procedure through a contract term stipulating for arbitration. Moreover, reliance on such informal systems is particularly problematic because one loses the "public goods" associated with more formal litigation: development of a set of precedents; public revelation of information about such important policy matters as accident rates; and, relevant to this Symposium, the use of judicial decision to propagate and reinforce social norms. ${ }^{18}$ Note that all of these are goods that the parties themselves-particularly powerful repeat transactors-would have no incentive to consider or, indeed, may see as costs to themselves, although they are benefits from the social point of view. ${ }^{19}$

${ }^{16}$ See Bernstein, supra note 1, at 1771-77; Ramseyer, supra note 1, at 1828-29.

${ }^{17}$ A powerful recent discussion is provided by Richard H. Pildes \& Cass R. Sunstein, Reinventing the Regulatory State, 62 U. CHI. L. REV. 1, 33-65 (1995).

${ }^{18}$ See generally Owen M. Fiss, Against Settlement, 93 YALE L.J. 1073 (1984) (preferring adjudication over alternative dispute resolution because, among other reasons, adjudication makes decisions public and sets precedents).

${ }^{19}$ Manufacturers of consumer goods reap obvious advantages from keeping product accident rates and safety standards secret. 


\section{When Should Norms Be Incorporated into Legal Rules?}

Bernstein's important work not only displays a system in which the transactors have subjected themselves to a formalized set of norms enforced through nonlegal sanctions. She argues as well that the internal operation of this norm system sheds light on an important question about norms-whether the legal system should enforce these norms in its regulation of transactions. She suggests, contrary to a generation of wisdom, that it should not, at least in the case of sales of goods governed by the UCC. I turn now to this second substantive conclusion of Bernstein's analysis: that Article 2 of the UCC incorrectly attempts to incorporate informal nonlegal norms into the parties' legal obligations as enforceable contract terms. As Bernstein observes, her attack is upon the fundamental premise of Article 2, as espoused by the drafter Karl Llewellyn. ${ }^{20}$

My colleague Mary Ann Glendon brilliantly depicts Karl Llewellyn as the Matisse of legal modernism. ${ }^{21}$ Matisse's quip that he wanted looking at his paintings to be as comfortable as sitting in a plush armchair ${ }^{22}$ is certainly consistent with this image. The peculiar comforts proffered by Article 2 of the UCC-some of whose provisions might seem to lack the requisite element of cozinesscame from the essentially clubby assumption that the rules of law should conform to, indeed, be derived from, the assumptions and understandings of the ordinary, honest transactor-a sort of merchant homme moyen sensuel who, finally, in the UCC, would find a set of rules that made sense to him.

Llewellyn could hardly have been motivated in his suggestion by a concern for "efficiency" in any of its contemporary senses; indeed, the various elements of this plural conception had hardly been formulated at the time that Llewellyn worked. ${ }^{23}$ Rather,

${ }^{20}$ Of course, although the fundamental premise, it is not uniformly implemented in the specific rules of Article 2. For example, as Bernstein recounts, the perfect tender rule is inconsistent-a bit of formalism that survived because of the overwhelming pressure of business persons to prevent their norms from being imported into the Code. See Bernstein, supra note 1 , at 1801.

${ }^{21}$ See MARY A. Glendon, A Nation UNDER LAWYERS: HOW THE Grisis IN THE LEGAL PROFESSION IS TRANSFORMING AMERICAN SOCIETY 191 (1994) ("If Holmes was the harsh, bold Picasso of legal modernism, Karl Llewellyn was its exuberant Matisse."). 1988).

${ }^{22}$ See Jack Flam, Introduction to MATISSE: A RETROSPECTIVE 21, 23 (Jack Flam ed.,

${ }^{23}$ See Russell Hardin, Magic on the Frontier: The Norm of Efficiency, 144 U. PA. L. REv. 1987 (1996) (discussing the development of the "efficiency norm" in law). 
Llewellyn's approach finds its roots most directly in a Hayekian belief in the wisdom and durability of embedded social norms, which the law would adopt if enlightened and would oppose at its peril. The merchant judges dreamed of by Llewellyn are of a piece with the wise men whom Hayek commended as judges for his common-law-based constitutional regime. ${ }^{24}$

Contemporary studies, founded in conceptions of game theory, present a considerably less benign, more agonistic picture of commercial relationships, correlatively questioning the adjudicative theories that found the organic approach to social norms advocated by Hayek and Llewellyn. The basic conception of the modern approach-in sharp contradistinction to that of Hayek and Llewellyn-is that the rules that parties follow when they play among themselves are not those that a court should attempt to apply. Here, Bernstein's work is exemplary.

Of course, commentators have long argued that the norms that ordinarily govern commercial life should not be incorporated into the legal standards for contract enforcement. ${ }^{25}$ Bernstein's contribution is to display in detail a private commercial system that apparently fits the commentators' predictions. Unfortunately, on the basis of evidence from NGFA practice, one can go only a small way toward endorsing a sharp separation between commercial norms and legal rules or, particularly, rejecting the jurisprudential approach of the UCC.

Of course, it is inevitable that basic commercial systems-under any plausible system of adjudication-define certain basic conceptions by reference to the underlying commercial practices that give these conceptions meaning. Thus, for example, the NGFA offers practice-oriented definitions for such seemingly elementary terms as "buy," "sell," "deliver," "confirmation," and "price." Llewellyn understood-and NGFA practice confirms-that such terms cannot

24 On this strand of Hayek's work, see Richard Bellamy, "Dethroning Politics": Liberalism, Constitutionalism and Democracy in the Thought of $F$. A. Hayek, 24 BRIT. J. POL. ScI. 419, 426-28 (1994) (discussing the substance of Hayek's constitutional scheme whereby "legislators" would be accountable to moral principles rather than the self-interested will of the majority). The common intellectual influences among Hayek, Llewellyn, and other thinkers in this tradition are described by James Whitman, Note, Commercial Law and the American Volk: A Note on Llewellyn's German Sources for the Uniform Commercial Code, 97 YALE L.J. 156 (1987).

${ }^{25}$ See, e.g., David Charny, Nonlegal Sanctions in Commercial Relationships, 104 HARV. L. REV. 373 (1990) (discussing the effects of nonlegal sanctions on commercial transactions and arguing for a legal system that will not give estoppel effect to those commitments not intended to be legally enforceable). 
be defined in a formalistic vacuum. Beyond these definitions, the NGFA code is in large part a compendium of industry norms, and the main virtue of nonjudicial arbitral decisionmaking is the ability to apply uncodified expertise about industry custom when interpreting particular agreements or fact patterns. In these circumstances, it would be merely ironic to assert that NGFA transactors have adopted a code designed to exclude application of various industry "norms" to their disputes. In fact, it is not clear that the NGFA is up to anything inconsistent with what was contemplated by UCC jurisprudence. Clearly, something more complicated than the simple exclusion of custom is at work.

Most evidently, transactors (at least, those transactors who act through the industry association) have selected some norms for enforcement but not others. Apparently, what the norm selectors are aiming for is uniformity. But how did they pick and choose among the various norms on offer? It is tempting to conclude, as Bernstein hints, that large transactors may have been choosing to enforce the norms that served their own interests. Or they may have chosen simple "focal point" norms, even though these were not substantively the most efficient. So the practice of the Association may not indicate that there is a gap between the norms followed by transactors and the substance of the rules that it would be desirable for courts to enforce.

Nor can one infer from the grain and feed regime that the parties would not wish norms to be enforced through the courts when their disputes ended up there-particularly when there was no substitute enforcement system available. For the UCC drafters, the question of norm incorporation had to be decided as an entirely general manner-ironically, abstracting from particular circumstances of particular industries to which the UCC would end up applying. From this perspective, it is hard to conclude from Bernstein's evidence that the drafters made the wrong choice. Clearly, grain and feed transactors prefer that a fairly elaborate set of norms be enforced when they take disputes to third-party dispute resolution. Would such transactors really wish that courts ignore all of these norms if the more informal third-party system were not available? Of course, it is possible that the courts are so likely to "get it wrong," and at elaborate expense, that the parties would prefer a highly formalistic system, but it is equally possible that the parties would prefer an occasionally erroneous effort to apply their norms over legal rules that made no attempt at all to make sense of their commercial practice. What we need, of course, is not an a 
priori speculation, but evidence of their preference-and the evidence to date points equally in both directions. ${ }^{26}$

Indeed, it is difficult to know what types of evidence would count for this because of the purported difficulty of "opting out" of the UCC's interpretive sections about custom. Presumably, one would like to measure the extent to which parties incurred costs to opt out of particular norms. But this creates a paradoxical situation: if parties are frequently opting out, then the costs of doing so are presumably not that great, and the case for law reform weakens considerably. ${ }^{27}$ Conversely, if opt-outs are expensive to draft or risky to use, one may rarely observe them despite high costs imposed by the UCC's inappropriate rules. It is also hard to measure the number of transactions that do not go through at all because of the UCC's potentially stultifying rules.

Even if we accept that most parties conform to a body of nonlegal norms that they do not wish to see enforced, problems of interpreting this phenomenon remain. Let me mention two. First, the stipulated distinction between ongoing and end-game relationships, though provocative in this context and consistent with a large body of theoretical literature, is itself "endogenous" to the set of norms (and to the characteristics of the legal enforcement system) at issue. For example, workers continue to work for their employers through the period of union arbitration on issues of pay and promotion; if workers have been fired, they return to work after a finding of unlawful discharge. As the labor relationship illustrates, then, the norm itself-that litigation is inconsistent with a continuing relationship-is socially contingent.

I would propose-in part on the basis of Bernstein's evidencethat the crucial distinction would be one between sharing norms and punitive norms. Parties split the losses when they are amicable; but

${ }^{26}$ The Solomonic compromise proposed at the end of Bernstein's article-making it easier for the industry to opt out-is clearly appealing, see Bernstein, supra note 1 , at 1821, but it does not address the UCC drafter's central dilemma: that of adopting interpretive conventions to be codified in a general statute as applicable, in the absence of contrary indications, across the board.

${ }^{27}$ Note that-contrary to what many commentators assume-the UCC's default rule may be appropriate even though most parties opt out of it. The pertinent question is the costs of opt-out as contrasted to the costs of alternative rules. See generally David Charny, Hypothetical Bargains: The Normative Structure of Contract Interpretation, 89 MICH. L. REv. 1815, 1847-48 (1991). A more formalistic UCC could impose very high costs on the small group of transactors who rely to their detriment on informal norms; avoidance of these latter costs arguably would justify the relatively small costs imposed on sophisticated transactors who wish to opt out of UCC informalism. 
when one party willfully or egregiously violates a norm, the other party (or the system) punishes the wrongdoer-formally, imposes losses on the wrongdoer greater than the gains the wrongdoer would have derived from his wrongful conduct. In labor economics, for example, the "shirking" worker must face a punishment far greater than the benefits gained by him from shirking (loss of job, with consequent sacrifice of a "bond") in order to create incentives not to shirk. But application of a punitive norm need not end the relationship for all transaction-types-the repentant shirking worker seems at times to have been accepted back into the fold.

Second, before drawing normative conclusions for practices linked to "norms," one must assure that the relevant transactors are properly informed about the norms at issue, as well as about facts pertinent to norm formulation and application. One ground for judicial intervention to enforce or modify norms is to correct parties' mistakes about what norms apply or how effective the sanctions that enforce the norms outside of the law are. ${ }^{28}$ For example, naive parties may be the victim of exploitative conduct-a form of socially wasteful "rent-seeking"-by their more sophisticated counterparts, and transactions by misinformed parties may misallocate resources, from a social point of view. Bernstein's analysis suggests that there may be a class of naïve transactors: transactors who lack the skill and "technology" (like lawyers or a bureaucracy) for careful form contracting, and who may rely mistakenly on informal norms. For these transactors, the UCC norms of informality may provide substantial and justified protections.

\section{CONCLUSION}

All of this leads up to a concluding comment about the methodology of a conception of "norms." Here, as always, it is crucial to distinguish between positive and normative uses of the conception. For positive work, the conception of norms continues to generate stimulating and powerful hypotheses on transactional systems, as exemplified in this Symposium by the important work of Bernstein and of Johnston on the UCC. As a normative matter, however, I am skeptical that economic analysis can generate, through notions such as "efficiency," a useful set of social judgments

${ }^{28}$ See generally Charny, supra note 25, at 426-46 (arguing that legal decisionmakers may improve the position of transactors by enforcing nonlegal commitments). 
about norms. There are simply too many unobservable variables, particularly those that bear on the "noneconomic" motivations and preferences that must play a role in the start-up and the effectiveness of complex sanctioning systems.

For a normative perspective, then, one is led to return to the Hayekian roots of the current interest in norms. Hayek's insistence on the impenetrability of human preferences-and, correspondingly, the impossibility of their satisfaction through centralized institutions-might have provided a stronger ground (at least, than anything in modern welfare economics) for a presumptive judgment in favor of nonlegal normative systems. The normative project, then, would be to describe, not only the efficiency but also the other, as yet, largely inchoate or unarticulated social virtues of these systems. Ironically, then, it would be in the irrationality, not the rationality, of social actors that the authority of these systems is ultimately grounded. 